\title{
STUDI PENGARUH KEMIRINGAN, JARAK, DAN PANJANG SOIL NAILING TERHADAP STABILITAS LERENG
}

\author{
Melin Ester Simorangkir ${ }^{1}$ dan Andryan Suhendra² \\ ${ }^{1}$ Program Studi Sarjana Teknik Sipil, Universitas Tarumanagara, Jl. Letjen S. Parman No.1 Jakarta \\ call.ester@yahoo.com \\ ${ }^{2}$ Program Studi Sarjana Teknik Sipil, Universitas Tarumanagara, Jl. Letjen S. Parman No.1 Jakarta \\ andryansuhendra@yahoo.com
}

\begin{abstract}
A landslide happened at a slope in South Sulawesi. The slope has 4 soil layers with a height of $15 \mathrm{~m}$ and a slope angle of $69,86^{\circ}$. Stability of the slope needs to be analized with a program based on limit equilibrium to know the value of its safety factor. After being analyzed, the safety factor of the slope is 0,883, which is less than 1,5. It shows that the slope need a soil reinforcement. For this analysis, soil nailing is being used to be the soil reinforcement. With using soil nailing, the stability of the slope needs to be analyzed again with a program based on limit equilibrium. In each analysis, there are some variations. The first analysis is a variety of nail inclination. The second analysis is a variety of nail spacing. The third analysis is a variety of nail length. The result of the safety factor of all analysis is more than minimal, 1,5 .
\end{abstract}

Keywords: stability of slope; safety factor; soil nailing

\begin{abstract}
ABSTRAK
Pada suatu lereng di daerah Sulawesi Selatan, terjadi longsor. Lereng yang mengalami longsor tersebut memiliki 4 lapisan tanah dengan ketinggian lerengnya $15 \mathrm{~m}$ dan kemiringan lerengnya $69,86^{\circ}$. Stabilitas lereng perlu dianalisis menggunakan sebuah program berbasis metode kesetimbangan batas untuk mengetahui nilai keamanan lereng tersebut. Setelah dianalisis, diketahui nilai keamanan lereng di bawah 1,5 , yaitu 0,883. Nilai keamanan lereng tersebut menunjukkan bahwa lereng tersebut membutuhkan sebuah metode perkuatan tanah. Pada analisis ini, metode perkuatan tanah yang digunakan pada lereng adalah soil nailing. Dengan menggunakan soil nailing, dilakukan analisis stabilitas lereng kembali menggunakan program berbasis metode kesetimbangan batas untuk memperoleh angka faktor keamanan lereng. Di setiap analisis menggunakan soil nailing, digunakan beberapa variasi nail. Analisis stabilitas lereng pertama menggunakan variasi kemiringan nail. Analisis stabilitas lereng kedua menggunakan variasi jarak antar nail. Analisis stabilitas lereng ketiga menggunakan variasi panjang nail. Hasil akhir faktor keamanan lereng setelah dilakukan semua analisis adalah lebih dari 1,5.
\end{abstract}

Kata kunci: stabilitas lereng; faktor keamanan; soil nailing

\section{PENDAHULUAN}

Indonesia mempunyai wilayah yang luas. Setiap wilayahnya mempunyai keadaan tanah yang berbeda dengan keunikannya masing. Keadaan yang banyak ditemukan di Indonesia adalah tanah berlereng. Kondisi lereng berbeda-beda, tergantung jenis tanah, kemiringan lereng, dan perbedaan elevasinya. Lereng bisa terbentuk secara alamiah yang disebabkan oleh kondisi kontur. Lereng juga bisa terbentuk oleh buatan manusia melalui proses penggalian. Dengan kata lain, lereng adalah kondisi permukaan tanah dengan elevasi berbeda pada sudut kemiringan tertentu yang diukur dari arah horizontal.

Pada keadaan tertentu, lereng bisa menjadi tidak stabil. Ketidakstabilan ini mengakibatkan suatu kegagalan yang biasa disebut kelongsoran. Banyak faktor yang bisa menjadi penyebab dari kegagalan lereng ini. Faktor-faktor tersebut menyebabkan tanah tidak mampu menahan tegangan geser yang terjadi pada lereng. Ini sangat berbahaya. Longsor yang terjadi dapat mengancam keselamatan orang-orang di sekitar lereng dan juga dapat merusak bangunan konstruksi yang dibangun di sekitar longsor. Oleh karena itu, kegagalan lereng harus dicegah. Stabilitas lereng dan parameter tanah perlu dianalisis dengan memperhitungkan faktor keamanannya. Faktor keamanan yang tinggi mengurangi angka potensi kegagalan lereng yang mungkin terjadi. Hasil dari analisis dapat digunakan untuk menentukan metode perkuatan lereng yang dibutuhkan dan paling efisien. 
Salah satu metode perkuatan lereng yaitu soil nailing. Soil nailing adalah metode perkuatan tanah untuk stabilisasi lereng dengan cara melakukan pemakuan batang-batang, seperti baja dan mini pile (Lazarte, 2003). Soil nailing memanfaatkan tekanan pasif yang akan bekerja saat terjadi gerakan. Oleh karena itu, metode ini mampu mempertahankan galian, menstabilkan lereng, dan membentuk perkuatan penahan tanah. Dalam studi ini, akan dibahas pengaruh kemiringan dan kedalaman soil nailing yang dipasang pada stabilitas lereng. Melalui analisis yang dilakukan, akan diperoleh kemiringan dan kedalaman optimal dari soil nailing yang dibutuhkan.

Identifikasi masalah dalam penelitian ini adalah kemiringan, jarak, dan panjang soil nailing yang paling optimal berdasarkan kondisi lereng dan parameter tanah yang ada.

Berikut batasan masalah dalam penelitian ini.

1. Lokasi lereng

Lereng yang mengalami kelongsoran berada di daerah Sulawesi Barat

2. Ketinggian lereng adalah 15 meter.

3. Soil nailing untuk perkuatan stabilitas lereng dengan kemiringan nail tertentu

4. Soil nailing untuk perkuatan stabilitas lereng dengan jarak antar nail tertentu

5. Soil nailing untuk perkuatan stabilitas lereng dengan panjang nail tertentu

Berikut rumusan masalah dalam penelitian ini.

1. Pengaruh kemiringan nail pada soil nailing untuk perkuatan stabilitas lereng

2. Pengaruh jarak antar nail pada soil nailing untuk perkuatan stabilitas lereng

3. Pengaruh panjang nail pada soil nailing untuk perkuatan stabilitas lereng

4. Besar kemiringan, panjang, dan jarak antar soil nailing yang maksimal untuk perkuatan stabilitas lereng

Berikut tujuan dari penelitian ini.

1. Mengetahui pengaruh kemiringan nail pada soil nailing untuk perkuatan stabilitas lereng.

2. Mengetahui pengaruh jarak antar nail pada soil nailing untuk perkuatan stabilitas lereng.

3. Mengetahui pengaruh panjang nail pada soil nailing untuk perkuatan stabilitas lereng.

4. Mengetahui besar kemiringan, panjang, dan jarak antar soil nailing yang maksimal untuk perkuatan stabilitas lereng.

\section{Lereng}

Lereng merupakan permukaan tanah tidak merata dengan sudut kemiringan tertentu yang diukur dari bidang horizontal. Keadaan lereng harus stabil. Pada keadaan terntentu, lereng bisa menjadi tidak stabil. Ketidakstabilan ini mengakibatkan suatu kegagalan yang biasa disebut kelongsoran. Longsor yang terjadi dapat mengancam keselamatan orang-orang di sekitar lereng dan juga dapat merusak bangunan konstruksi yang dibangun di sekitar longsor. Untuk mampu mengatasinya, dibutuhkan analisis stabilitas lereng untuk mengetahui faktor keamanan yang tepat.

\section{Stabilitas lereng}

Stabilitas lereng dipengaruhi oleh nilai kuat geser yang seharusnya lebih besar daripada tegangan geser.

Berikut ini penyebab terjadi kegagalan stabilitas lereng.

1. Tegangan air pori mengalami peningkatan

Saat terjadi hujan dalam waktu yang lama pada daerah tertentu, akan terjadi kenaikan muka air dan juga rembesan pada lereng. Hal ini menyebabkan berkurangnya tegangan efektif dan kuat geser lereng. Beban pada lereng juga menjadi bertambah dan menyebabkan lereng tidak stabil dan terjadi peningkatan tegangan geser lereng.

2. Keretakan pada puncak lereng

Hal ini dikarenakan gaya tarik pada permukaan lebih besar daripada kuat tarik dalam tanah. Keadaan ini dinamakan tension crack.

3. Pelapukan pada batuan

Saat batuan mengalami pelapukan, kuat geser pada lereng akan hilang sehingga tidak ada ikatan dengan batuan induk.

4. Penggalian pada kaki lereng

Hal ini menjadikan lereng curam dan terjadi peningkatan tegangan geser.

Berikut ini faktor yang mempengaruhi kestabilan lereng.

1. Struktur batuan 
Untuk menganalisis stabilitas lereng, penting menyelidiki struktur batuan yang terdapat pada lereng agar dapat diketahui bidang-bidang sesar, rekahan, dan lipatan yang bisa menjadi penyebab terjadinya longsor batuan.

2. Geometri lereng

Geometri lereng yang dimaksud adalah kemiringan dan ketinggian lereng. Jika lereng semakin curam, semakin besar potensi terjadi ketidakstabilan lereng.

3. Sifat fisik dan mekanik batuan

Batuan memiliki sifat fisik porositas, density, dan moisture content. Mekanik batuan meliputi sudut geser, kuat tarik, kuat geser, dan kohesi.

4. Topografi

Berdasarkan topografinya, bisa diperoleh laju erosi dan pengendapan yang terjadi pada lereng.

\section{Faktor keamanan stabilitas lereng}

Faktor keamanan adalah hal penting dalam analisis stabilitas lereng. Dengan mengetahui faktor keamanan, dapat diketahui terjadi atau tidaknya keruntuhan pada lereng. Ketentuan untuk faktor keamanan berdasarkan pertimbangan biaya dan konsekuensi kegagalan lereng terhadap ketidakpastian kondisi analisis lereng dapat dilihat pada Tabel 1 .

Tabel 1. Nilai faktor keamanan untuk lereng tanah

\begin{tabular}{|c|c|c|}
\hline \multirow{2}{*}{ Biaya dan Konsekuensi Kegagalan Lereng } & \multicolumn{2}{|c|}{$\begin{array}{l}\text { Tingkat Ketidakpastian } \\
\text { Kondisi Analisis }\end{array}$} \\
\hline & Rendah $^{\mathrm{a}}$ & Tinggi ${ }^{b}$ \\
\hline $\begin{array}{l}\text { Biaya perbaikan sebanding dengan biaya tambahan untuk } \\
\text { merancang lereng yang lebih konservatif } \\
\text { Biaya perbaikan lebih besar dari biaya tambahan untuk } \\
\text { merancang lereng yang lebih konservatif }\end{array}$ & 1,25 & 2,0 atau lebih \\
\hline \multicolumn{3}{|c|}{$\begin{array}{l}\text { Tingkat ketidakpastian kondisi analisis dikategorikan rendah jika kondisi geologi dapat dipahami, } \\
\text { kondisi tanah seragam, penyelidikan tanah konsisten, lengkap, dan logis terhadap kondisi di } \\
\text { lapangan. } \\
\text { b Tingkat ketidakpastian kondisi analisis dikategorikan tinggi jika kondisi geologis sangat kompleks, } \\
\text { kondisi tanah bervariasi, dan penyelidikan tanah tidak konsisten dan tidak dapat diandalkan. }\end{array}$} \\
\hline
\end{tabular}

Ketentuan untuk lereng batuan berdasarkan kondisi permanen maupun sementara dapat dilihat pada Tabel 2.

Tabel 2. Rekomendasi nilai faktor keamanan untuk kereng batuan

\begin{tabular}{cc}
\hline Kondisi Lereng Batuan & Rekomendasi Nilai Faktor Keamanan \\
\hline Kondisi permanen & 1,5 \\
Kondisi sementara & 1,3 \\
\hline
\end{tabular}

(Sumber : SNI Persyaratan Perancangan Geoteknik, 2017)

\section{Analisis stabilitas lereng}

Dalam analisis stabilitas lereng, terdapat 2 prosedur yang bisadigunakan, yaitu sebagai berikut.

1. Prosedur massa (mass procedure)

Prosedur ini digunakan untuk lereng yang tanahnya homogen. Pada prosedur massa, analisis menggunakan metode perhitungan stabilitas lereng dengan kondisi $\varnothing=0$.

2. Metode irisan (method of slices)

Pada metode irisan, bidang gelincir terbagi menjadi beberapa irisan vertikal dan akan dianalisis stabilitas dari masing-masing irisan. Denganmenggunakan metode ini, perhitungan stabilitas teliti karena tanahnya tidak homogen dan perbedaan tekanan pori dapat dimasukkan ke dalam perhitungan. Berikut metode yang bisa digunakan, yaitu metode Fellenius dan metode Bishop. Faktor keamanan dihitung berdasarkan keseimbangan momen. Diasumsikan kelongsoran terjadi melalui rotasi dari suatu irisan tanah pada permukaan bidang 
longsor. Metode ini efektif jika kondisi lereng adalah isotropis, non-isotropis,, dan berlapis-lapis. Pada metode ini, terdapat beberapa massa tanah yang bergerak menjadi irisan vertikal. Antar irisan belum tentu sama lebarnya sehingga bisa membentuk dasar lengkung busur yang dianggap garis lurus. Pada metode Bishop, semua gaya yang bekerja pada setiap sisi dari masing-masing irisan diperhitungkan.

\section{Soil nailing}

Salah satu metode perkuatan lereng adalah penggunaan soil nailing. Soil nailing adalah perkuatan lereng menggunakan batang baja yang dipasang dengan jarak dekat ke dalam lereng untuk memindahkan beban ke tanah sekitar soil nailing. Soil nailing dapat meningkatkan gaya normal dan gaya perlawanan geser tanah selama terjadi potensial bidang geser tanah dan juga mengurangi daya dorong yang terjadi antara gesekan pada tanah kohesif bidang gelincir.

Berikut jenis tanah yang tepat untuk penggunaan soil nailing.

1. Stiff to hard fine - grained soil

Tanah berbutir halus atau tanah kohesif yang termasuk dari stiff to hard clays, clayey silts, silty clays, dan sandy silts yang memiliki nilai N-SPT > 9

2. Dense to very dense granular soils

Tanah yang terdiri dari pasir dan batuan (non-kohesif)nyang memiliki nilai N-SPT > 30

3. Batuan lapuk yang tidak mempunyai bidang diskontinu

Batuan lapuk mampu menjadi pendukung dalam penggunaan soil nailing. Pelapukan yang terjadi harus seragam. Jika tidak, akan mempersulit proses pengeboran dan pemasangannya.

\section{Komponen soil nailing}

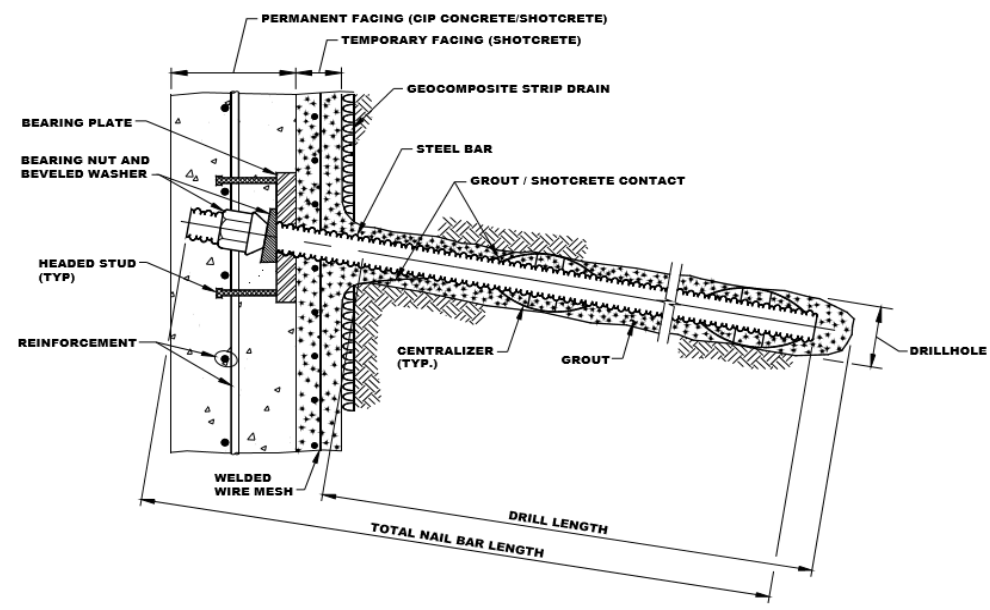

Gambar 1. Komponen soil nailing (Sumber : Geotechnical Engineering Circular No. 7 Soil Nail Walls, 2003)

Berikut ini komponen-komponen utama pada soil nailing berdasarkan Gambar 1.

1. Batang baja (nail bars)

Batang baja yang digunakan sebaiknya mempunyai kuat tarik $420 \mathrm{MPa}$ atau $520 \mathrm{MPa}$. Diameter yang optimal adalah $19 \mathrm{~mm}, 22 \mathrm{~mm}, 25 \mathrm{~mm}, 29 \mathrm{~mm}, 32 \mathrm{~mm}, 36 \mathrm{~mm}$, dan 43. Berikut pola nail bars yang bisa digunakan.

2. Nail head

Nail head terdiri dari bearing plate, hex nut, washers, dan headed stut. Bearing plate berfungsi untuk mendistribusikan gaya pada ujung batang baja ke shotcrete. Bearing plate yang digunakan adalah baja dengan Fy 250 Mpa berbentuk persegi ukuran 200-250 mm dengan tebal $19 \mathrm{~mm}$. Washers dan hex nut dipasang untuk mengikat nail bars yang keluar.

3. Grout

Untuk grout, berdasarkan ASTM C 150, tipe semen yang dgunakan adalah tipe I, II, III, dan V. Rasio air semen yang digunakan sekitar 0,4-0,5. Kuat tekan grout harus mencapai $21 \mathrm{MPa}$ dalam 28 hari.

4. Centralizer

Komponen ini terdiri dari polivinil clorida (PVC) atau bahan sintetis lain. Ini dipasang di sepanjang nail bars agar tebal selimut beton sesuai dengan rencana dengan jarak $\leq 2,5 \mathrm{~m}$ dan $0,5 \mathrm{~m}$.

5. Proteksi korosi 
Proteksi korosi berupa corrugated sheath dari material sintetik dengan tebal minimal $1 \mathrm{~mm}$.

6. Wall facing

Tampilan dinding terdiri dari 2 tahap. Untuk tahap pertama, tampilan dinding sementara dibuat dari shotcrete selama pekerjaan kontruksi berlangsung. Ini bertujuan untuk melindungi permukaan galian dari erosi. Untuk tahap kedua, tampilan dinding permanen dibuat dari beton pracetak. Ini membuat permukaan galian terlihat lebih rapi.

7. Sistem drainase

Sistem drainse berfungsi untuk mencegah peningkatan tekanan air di belakang dinding galian. Saluran drainse dibuat dari geokomposit dan dipasang di antara tampilan dinding sementara.

\section{Syarat komponen dinding soil nailing}

Berikut syarat penting dalam membentuk dinding soil nailing menurut SNI Persyaratan Perencanaan Geoteknik (2017:217).

1. Kemiringan dinding

Kemiringan dinding mampu mengurangi kebutuhan panjang nail bar. Kemirngan $10 \%$ dari vertikal bisa mengurangi kebutuhan panjang nail bar 10\% - 15\% dibanding dinding tegak. Pada umumnya, kemiringan dinding soil nailing sekitar $80^{\circ}-90^{\circ}$ terhadap bidang horizontal.

2. Kemiringan nail

Syarat kemiringannya adalah $10^{\circ}-20^{\circ}$ di bawah bidang horizontal.

3. Panjang nail bar

Syarat panjangnya adalah $0,6 \mathrm{H}-1,2 \mathrm{H}$, di mana $\mathrm{H}$ adalah kedalaman dari galian.

4. Jarak antar nail

Syarat jarak untuk metode pemasangan untuk metode drilled and grouting soil nailing adalah 1,5 m. Syarat jarak untuk metode driven soil dan nailing adalah $1 \mathrm{~m}-1,2 \mathrm{~m}$. Pada baris pertama, nail bar harus dipasang $\leq$ 1,1 $\mathrm{m}$ di bawah puncak dinding agar terhindar dari longsor pada awal tahap galian.

5. Diameter lubang bor

Syarat diamternya adalah sekitar $100 \mathrm{~mm}-200 \mathrm{~mm}$.

\section{METODE PENELITIAN}

\section{Metodologi penelitian}

Tahapan penelitian dapat dilihat pada Gambar 2:

1. Pengumpulan data

Data tanah diambil dari hasil bore log Universitas Hasanuddin.

2. Studi literature

Untuk melakukan analisis ini, perlu mempunyai pengetahuan dan informasi mengenai stabilitas lereng, masalah kelongsoran, perkuatan tanah, dan juga cara kerja dari soil nailing. Teori-teori tersebut diperoleh dari literatur yang terkait.

3. Analisis data

Data yang diperoleh dikorelasikan untuk mendapatkan parameter-parameter tanah yang dibutuhkan.

4. Hasil perhitungan

Dari analisis dan perhitungan yang dilakukan, akan diperoleh nilai faktor keamanan dari masing-masing variabel (kemiringan dan kedalalaman soil nailing).

5. Analisis hasil

Nilai faktor keamanan yang diperoleh dibandingkan dan harus sesuai dengan persyaratan. 


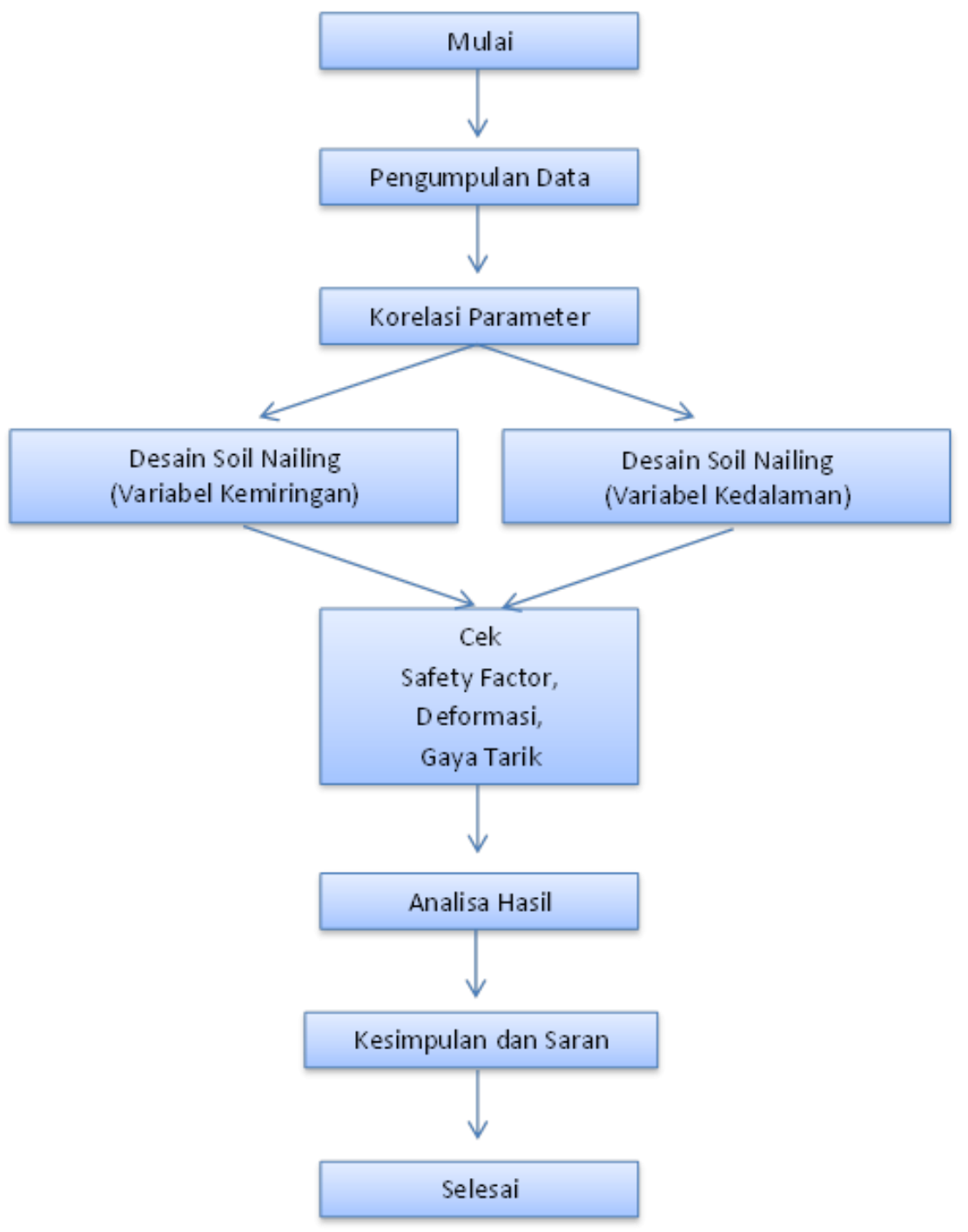

Gambar 2. Diagram alir penelitian

\section{HASIL DAN PEMBAHASAN}

Analisis stabilitas terhadap salahsatu lereng di daerah Sulawesi Barat dilakukan untuk memperoleh faktor keamanan yang paling optimal dengan menggunakan soil nailing sebagai metode perkuatan lereng. Dalam analisis ini, terdapat 3 hal yang divariasikan, yaitu kemiringan nail, jarak antar nail, dan panjang nail yang digunakan. Berdasarkan variabel tersabut, faktor keamanan lereng akan dianalisis menggunakan program berbasis metode kesetimbangan batas. Hasil faktor keamanan lereng dari masing-masing variabel akan dibandingkan sehingga dapat diperoleh faktor keamanan yang dibutuhkan. Melalui analisis ini juga, akan diketahui pengaruh kemiringan nail, jarak antar nail, dan panjang nail pada penggunaan soil nailing terhadap faktor keamanan lereng.

Berikut summary parameter tanah dari lereng tersebut yang diperoleh berdasarkan nilai N-SPT lereng.

Tabel 3. Summary parameter tanah

\begin{tabular}{clcccc}
\hline No. & Parameter Tanah & $\begin{array}{c}\text { Lapisan 1 } \\
(0-3.5 \mathrm{~m})\end{array}$ & $\begin{array}{c}\text { Lapisan 2 } \\
(3.5-7 \mathrm{~m})\end{array}$ & $\begin{array}{c}\text { Lapisan 3 } \\
(7-9.5 \mathrm{~m})\end{array}$ & $\begin{array}{c}\text { Lapisan 4 } \\
(9.5-20 \mathrm{~m})\end{array}$ \\
\hline 1. & $\begin{array}{l}\text { Berat volume } \gamma \\
\left(\mathrm{kN} / \mathrm{m}^{3}\right)\end{array}$ & 19,1 & 22 & 22 & 22 \\
2. & Kohesi c $\left(\mathrm{kN} / \mathrm{m}^{2}\right)$ & 20 & 60 & 60 & 60 \\
3. & Sudut geser $\phi\left(^{\circ}\right)$ & 32 & 40 & 40 & 40 \\
\hline
\end{tabular}




\section{Permodelan lereng tanpa perkuatan dengan program berbasis metode kesetimbangan batas}

Pada program berbasis metode kesetimbangan batas, dibuat model lereng dengan kemiringan $69,86^{\circ}$ yang terdiri dari 4 lapisan tanah. Parameter tanah yang sudah diperoleh juga dimasukkan ke dalam program. Berikut permodelan lereng tanpa perkuatan yang didapat.

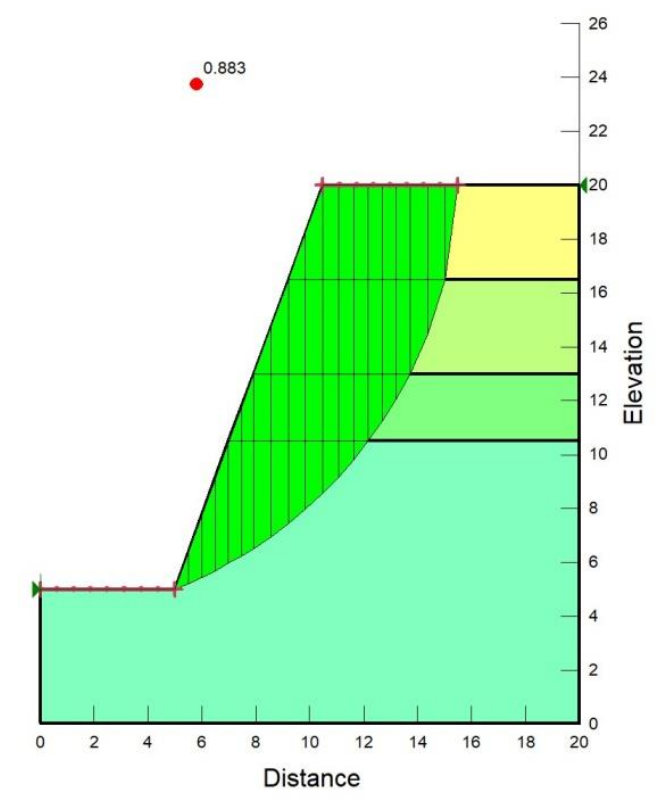

Gambar 3. Permodelan lereng tanpa perkuatan

Pada SNI Persyaratan Perancangan Geoteknik (2017), faktor keamanan untuk lereng dengan kondisi permanen seharusnya adalah 1,5. Dari hasil analisis stabilitas yang dilakukan terhadap lereng tanpa perkuatan melalui program, faktor keamanan dari lereng tersebut adalah 0,883. Hal ini menunjukkan lereng membutuhkan perkuatan tanah agar faktor keamanannya mampu mencapai nilai minimal 1,5. Perkuatan tanah yang digunakan adalah soil nailing.

\section{Permodelan lereng menggunakan soil nailing dengan program berbasis metode kesetimbangan batas}

Soil Nailing digunakan sebagai metode perkuatan dari lereng. Penggunaan soil nailing pada analisis menggunakan program berbasis metode kesetimbangan batas akan divariasikan kemiringan nail, jarak antar nail, dan panjang nail-nya. Dari semua hasil yang diperoleh, akan didapatkan faktor keamanan yang optimal.

1. Soil Nailing dengan Kemiringan Nail Tertentu

Pada analisis stabilitas lereng ini, kemiringan nail pada soil nailing akan divariasikan menjadi $0^{\circ}, 10^{\circ}, 20^{\circ}$, $30^{\circ}, 40^{\circ}, 50^{\circ}, 60^{\circ}, 70^{\circ}, 80^{\circ}$, dan $90^{\circ}$. Berikut faktor keamanan yang diperoleh.

Tabel 4. Faktor keamanan lereng dengan kemiringan nail tertentu

\begin{tabular}{ccc}
\hline No. & Kemiringan Nail & Faktor Keamanan \\
\hline 1. & $0^{\circ}$ & 2,041 \\
2. & $10^{\circ}$ & 2,032 \\
3. & $20^{\circ}$ & 2,023 \\
4. & $30^{\circ}$ & 2,002 \\
5. & $40^{\circ}$ & 1,980 \\
6. & $50^{\circ}$ & 1,951 \\
7. & $60^{\circ}$ & 1,909 \\
8. & $70^{\circ}$ & 1,881 \\
9. & $80^{\circ}$ & 1,832 \\
10. & $90^{\circ}$ & 1,810 \\
\hline
\end{tabular}

2. Soil Nailing dengan Jarak antar Nail Tertentu 
Pada analisis stabilitas lereng ini, jarak antar nail pada soil nailing akan divariasikan menjadi 3,8 m, 4 m, 4,2 m, 4,4 m, dan 4,6 m. Berikut faktor keamanan yang diperoleh.

Tabel 5. Faktor keamanan lereng dengan jarak antar nail tertentu

\begin{tabular}{ccc}
\hline No. & Jarak antar Nail & Faktor Keamanan \\
\hline 1. & $3,8 \mathrm{~m}$ & 2,042 \\
2. & $4 \mathrm{~m}$ & 2,041 \\
3. & $4,2 \mathrm{~m}$ & 2,038 \\
4. & $4,4 \mathrm{~m}$ & 2,035 \\
\hline
\end{tabular}

3. Soil Nailing dengan Panjang Nail Tertentu

Pada analisis stabilitas lereng ini, panjang nail pada soil nailing akan divariasikan menjadi 5,5 m, $6 \mathrm{~m}, 6,5 \mathrm{~m}$, $7 \mathrm{~m}$, dan 7,5 m. . Berikut faktor keamanan yang diperoleh.

Tabel 6. Faktor keamanan lereng dengan panjang nail tertentu

\begin{tabular}{ccc}
\hline No. & Panjang Nail & Faktor Keamanan \\
\hline 1. & $5,9 \mathrm{~m}$ & 1,978 \\
2. & $6,1 \mathrm{~m}$ & 2,042 \\
3. & $6,3 \mathrm{~m}$ & 2,042 \\
4. & $6,5 \mathrm{~m}$ & 2,042 \\
\hline
\end{tabular}

Terlihat dari Gambar 6, nail tidak mampu menembus seluruh bidang longsor sehingga panjng nail 5,9 m tidak bisa digunakan pada perkuatan lereng ini.

\section{Perbandingan faktor keamanan lereng dengan soil nailing}

Analisis lereng dengan perkuatan soil nailing menggunakan program berbasis metode kesetimbangan batas telah dilakukan dengan semua variasi nail yang direncanakan. Berikut summary dari hasil faktor keamanan yang diperoleh.

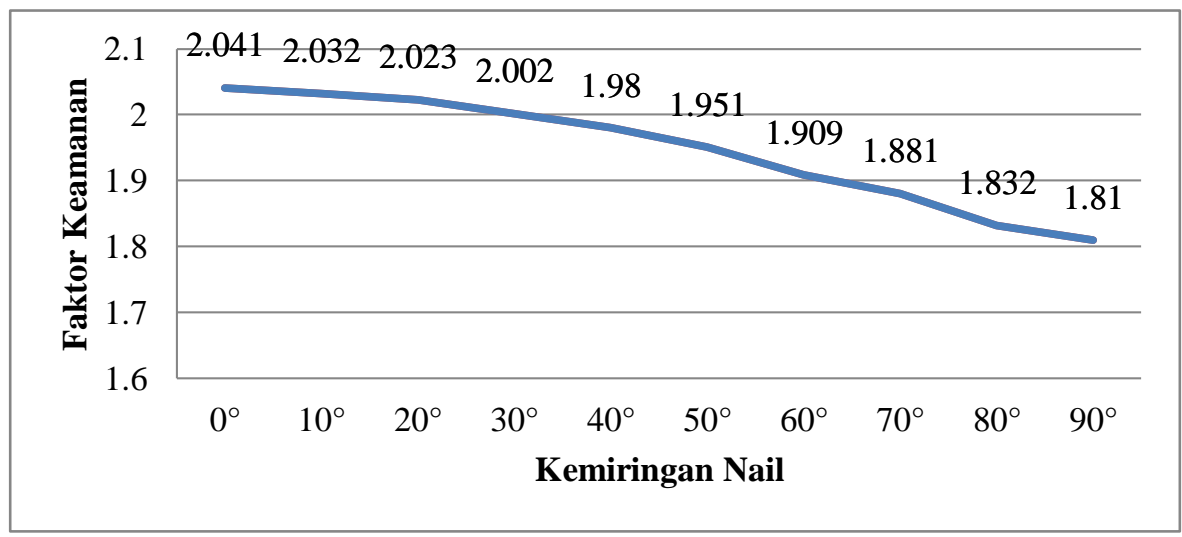

Gambar 4. Perbandingan faktor keamanan dengan kemiringan nail tertentu

Berdasarkan Gambar 4, didapatkan angka faktor keamanan tertinggi untuk stabilitas lereng adalah 2,041 pada kemiringan nail $0^{\circ}$. Namun, berdasarkan SNI Persyaratan Perencanaan Geoteknik (2017), kemiringan nail seharusnya $10^{\circ}-20^{\circ}$ di bawah bidang horisontal. Oleh karena itu, diambil nail dengan kemiringan $10^{\circ}$ sebagai faktor keamanan tertinggi, yaitu sebesar 2,032. Dari grafik tersebut, juga terlihat bahwa semakin besar kemiringan nail, angka faktor keamanannya menjadi menurun. 


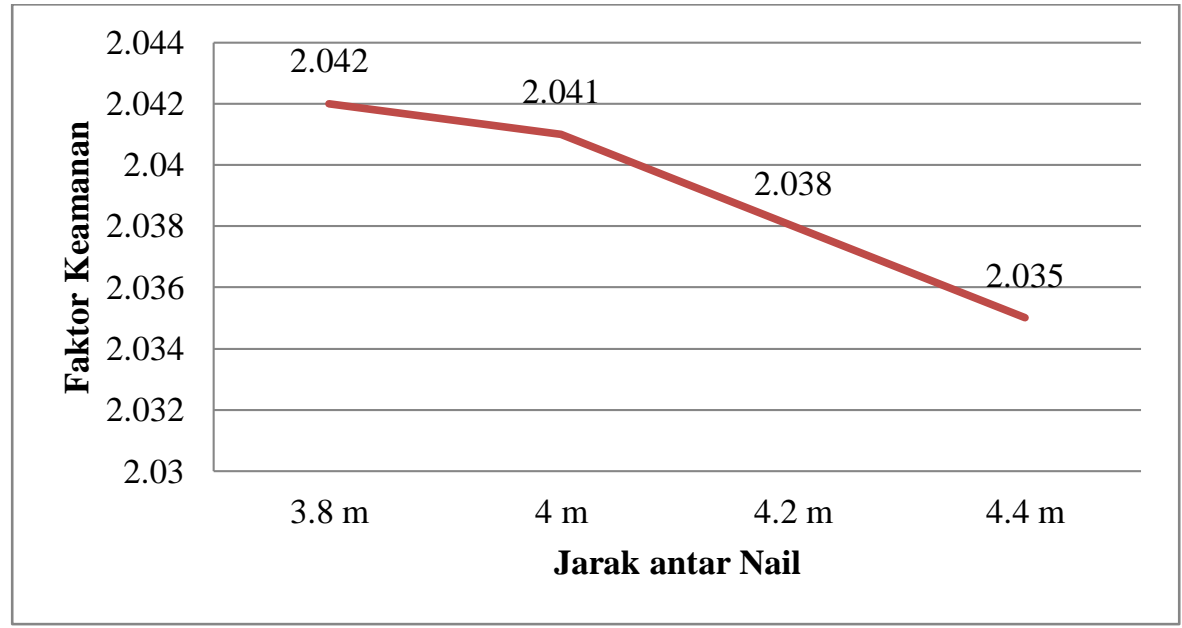

Gambar 5. Perbandingan faktor keamanan dengan jarak antar nail tertentu

Berdasarkan Gambar 5, didapatkan angka faktor keamanan tertinggi untuk stabilitas lereng adalah 2,042 pada jarak antar nail 3,8 m. Dari hasil tersebut, terlihat bahwa semakin besar jarak antar nail-nya, angka faktor keamananya menjadi menurun.

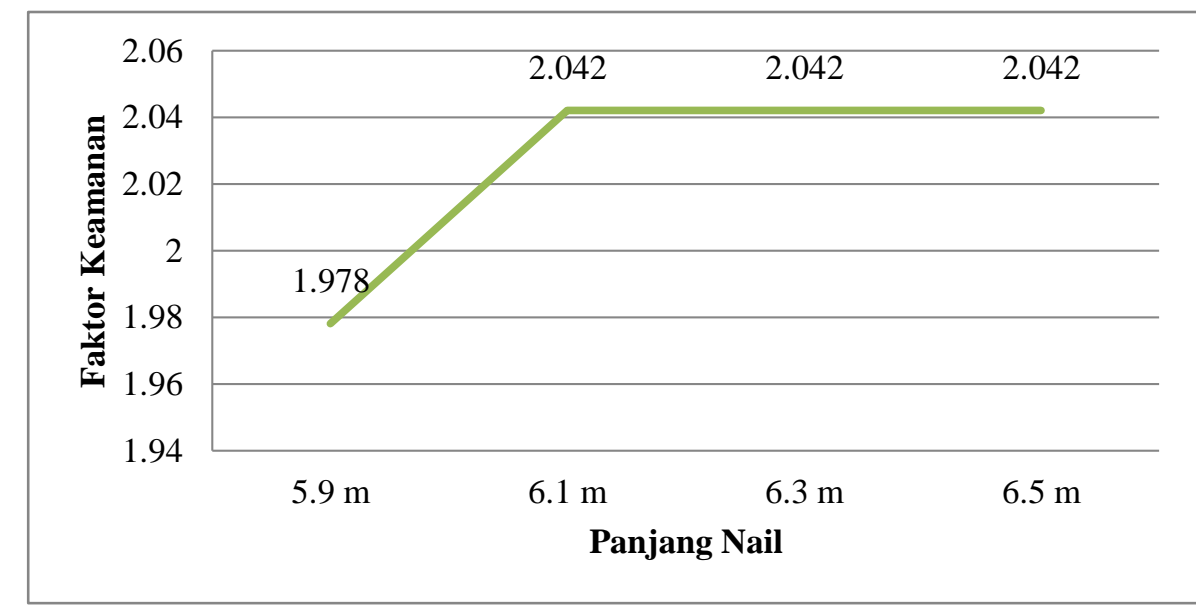

Gambar 6. Perbandingan faktor keamanan dengan panjang nail tertentu

Berdasarkan Gambar 6, terlihat bahwa angka faktor keamanan pada panjang nail 6,1 m, 6,3 m, dan 6,5 m adalah sama sehingga bisa disimpulkan bahwa angka faktor keamanan maksimal sebesar 2,042 bisa diperoleh pada panjang nail minimum, yaitu $6,1 \mathrm{~m}$.

\section{KESIMPULAN DAN SARAN}

\section{Kesimpulan}

Berdasarkan hasil analisis stabilitas lereng yang dilakukan terhadap salahsatu lereng di daerah Sulawesi Barat dengan perkuatan soil nailing menggunakan program berbasis metode kesetimbangan batas, dapat diperoleh kesimpulan sebagai berikut.

1. Lereng yang dianalisis mempunyai faktor keamanan sebesar 0,883 . Hal ini menunjukkan lereng belum mencapai angka stabilitas lereng minimal, yaitu 1,5 berdasarkan SNI Persyaratan Perancangan Geoteknik (2017).

2. Pada lereng yang dianalisis menggunakan soil nailing dengan variasi kemiringan nail, diperoleh angka faktor keamanan maksimal adalah 2,041 pada kemiringan nail $0^{\circ}$. Namun, berdasarkan SNI Persyaratan Perencanaan Geoteknik (2017), kemiringan nail seharusnya $10^{\circ}-20^{\circ}$ di bawah bidang horisontal. Oleh 
karena itu, diambil nail dengan kemiringan $10^{\circ}$ sebagai faktor keamanan maksimal, yaitu sebesar 2,032. Ini sudah memenuhi syarat angka stabilitas lereng minimal sebesar 1,5.

3. Pada lereng yang dianalisis menggunakan soil nailing dengan variasi jarak antar nail, diperoleh angka faktor keamanan maksimal adalah 2,042 pada jarak antar nail $3.8 \mathrm{~m}$. Ini sudah memenuhi syarat angka stabilitas lereng minimal sebesar 1,5 .

4. Pada lereng yang dianalisis menggunakan soil nailing dengan variasi panjang nail, diperoleh angka faktor keamanan maksimal adalah 2.042 pada panjang nail $6.1 \mathrm{~m}$. Ini sudah memenuhi syarat angka stabilitas lereng minimal sebesar 1,5 .

5. Untuk mencapai angka minimal stabilitas lereng sebesar 1.5, lereng yang dianalisis membutuhkan perkuatan soil nailing dengan nail sepanjang $6.1 \mathrm{~m}$ dengan kemiringan $0^{\circ}$ dan jarak antar nail $3.8 \mathrm{~m}$.

\section{Saran}

Berdasarkan analisis yang dilakukan, berikut ini saran untuk melengkapi kekurangan dari analisis ini.

1. Mengambil data lereng dari hasil uji laboratorium dan hasil bore log di lapangan.

2. Menambah titik di area lereng longsor yang dianalisis.

3. Melakukan analisis stabilitas lereng dengan mengganti metode perkuatan tanah

4. Melakukan analisis stabilitas lereng dengan mengganti model parameter tanah.

\section{DAFTAR PUSTAKA}

Badan Standarisasi Nasional. SNI 8460:2017. Persyaratan Perancangan Geoteknik. 2017. Jakarta: Badan Standarisasi Nasional.

Makarim, Chaidir A.,Yudhistira Y. Raynaldo, Alvin Tehmono. Pengantar Geologi \& Mekanika Tanah. 2017. Jakarta: Chaidir Anwar Makarim.

Lazarte, Carlos A., Victor Elias, David Espinoza, Paul J. Sabatini. Geotechnical Engineering Circular No.7 Soil Nail Walls. Publikasi FHWAO-IF-03-017. 2003. Washington, D.C: Federal Highway Administration. 